\title{
APPLICATION OF INCLINOMETER MEASUREMENTS FOR RELATIVE HORIZONTAL DISPLACEMENT INVESTIGATIONS ON LANDSLIDE GROUNDS
}

\author{
Ryszar Malarski, Kamil Nagórski, Marek Woźniak \\ Warsaw University of Technology \\ Faculty of Geodesy and Cartography \\ Department of Engineering Surveying \\ Warsaw, Poland
}

\begin{abstract}
One of the basic criterion for safety evaluation of structures erected on embankment or sliding slopes is relative horizontal displacement at different elevations. Relative horizontal displacements beneath ground surfaces are performed with inclinometer measurements.

This report presents results on horizontal relative ground displacements with the probe SISGEO S242SV30. Investigations were performed with two inclinometer columns $14 \mathrm{~m}$ height embedded in Warsaw Bank Slope. Mean square error of single observation was determined and mean relative errors of relative displacements in relation to column height.

On the basis measurement results several relevant recommendations and practical hints were formulated allowing to avoid survey blunders and discrepancies in measuring procedures often encountered.

Detailed inclinometer horizontal displacement measurements results at Warsaw hillside St Ana's Church grounds were listed and presented.
\end{abstract}

Keywords: displacement measurements, inclinometric measurements, monitoring

\section{Introduction}

Military objects, castles, sacred objects are usually constructed on elevated grounds where unfavourable geologic conditions for foundations are encountered. Location of such objects is chosen to satisfy obstructed access for an enemy due to safety measures and to obtain favourable vicinity over surrounding area. In case of sacred objects location there is an additional need to overlook adjacent buildings. 
Such a location has some essential drawbacks namely:

- escalation of soil weathering close to the structure,

- increased erosion effect,

- obstruction of ground water flow close to structure foundation,

- enhanced landslide effect.

Locations of historic structures are characterised by subsoil unstability and are almost always creating a potential source of risk to structure stability. On lowlands or with proximity to river valleys where loose structure soil exist a strong influence of subsoil water is inevitable. According to experience gained there is a constant need of strengthening constructions with foundation reinforcements, escarpment reinforcement with posts and electroosmosis and perpetual fixing of structural elements.

Due to historical value, costs consuming measures to save those monuments are undertaken.To cope with the problem and to cure the situation in an efficient way there is a must for monitoring displacements and deflections of each structure with geodetic and geotechnical methods and tools.

One of the most precious historical structures is undoubtedly St Ann's Church (Fig. 1.) threatened with disaster.

\section{Monitoring of Vistula slope and st. Anna's church deformation}

The Vistula slope and St. Anna's Church has been under supervising of surveyor staff from Warsaw University of Technology, Faculty of Geodesy and Cartography Department of Engineering Geodesy, since 2009.

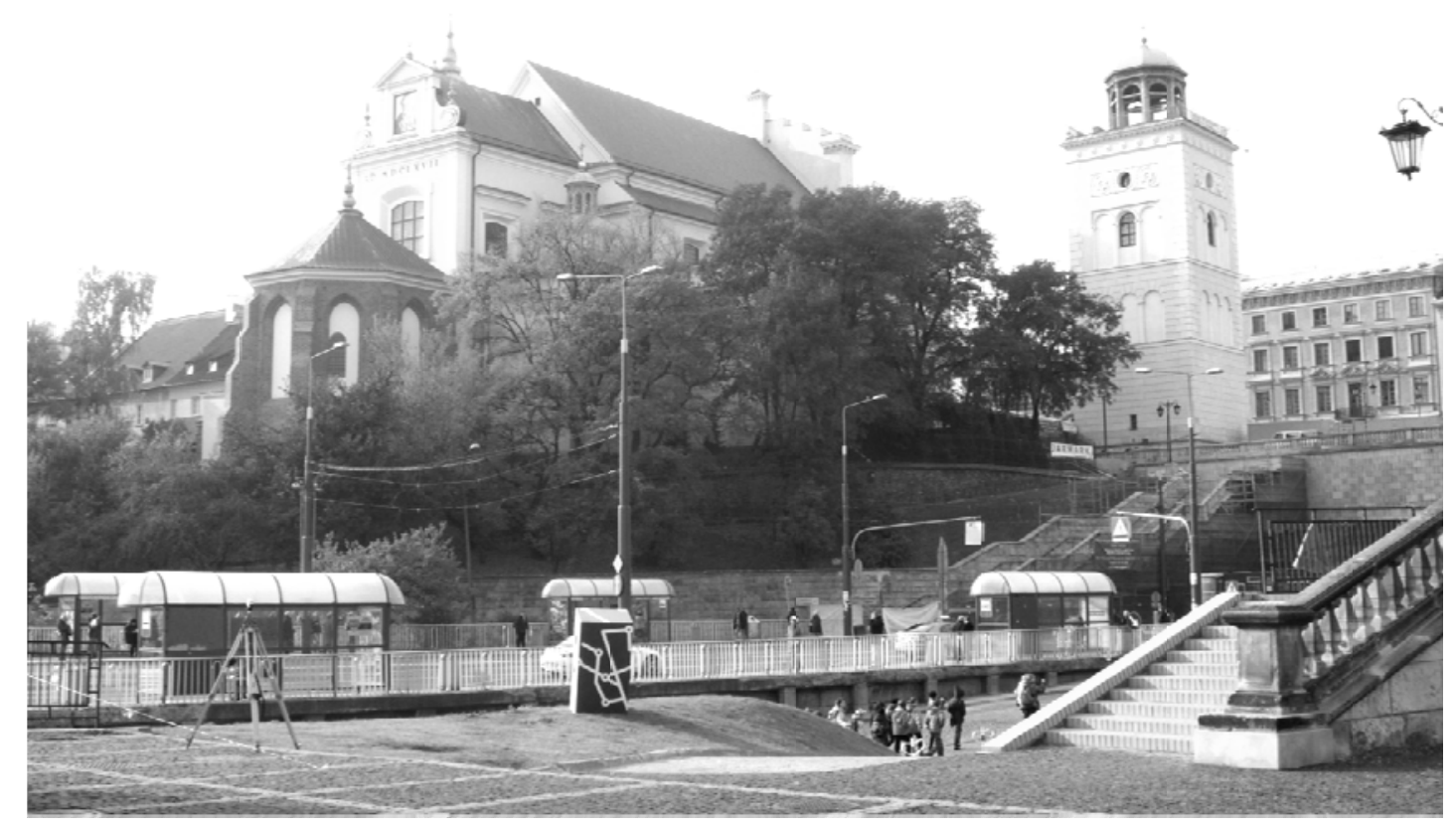

Fig. 1. A view of the church, the Gothic apse with buttresses and baroque gable dated back to 1667

St Anna's Church, the late Gothic Church famous for its classical front facade, is one of Warsaw oldest and most beautiful churches. Situated on the high Vistula slope, was founded in the mid 15th century by Princess Anna of Mazovia and given to the Bernardine monks. 
In 1949, during the construction of Warsaw's East-West Route, due to a failure to secure the slopes of a deep excavation, the walls and vaults of the church were cracked as deep as the foundation level. The apse and the north-eastern part of the church were slowly coming down. The immediate intervention of a commission of experts of various professions prevented the church from collapsing. The ground around the structure was reinforced with steel-concrete posts and electroosmosis, its foundations were embraced with reinforced concrete, and concrete retaining wall were built on excavation side.

Last years St Anna's Church has its difficult time again. Slits and fractures appeared on its floor, walls and vaults.

Comprehensive monitoring of the church, outlook tower (church belfry) slope retaining walls includes:

- determining vertical displacements by precise levelling method,

- determining of horizontal displacements by trigonometrical method with supplementary precise distance measurements,

- determining of cracks aperture and length and other wall and vault decays by photogrammetric method, tacheometric method and according to joint meter (clearance gauge) readings

In addition to surveying monitoring geotechnical investigations are to be carried out.

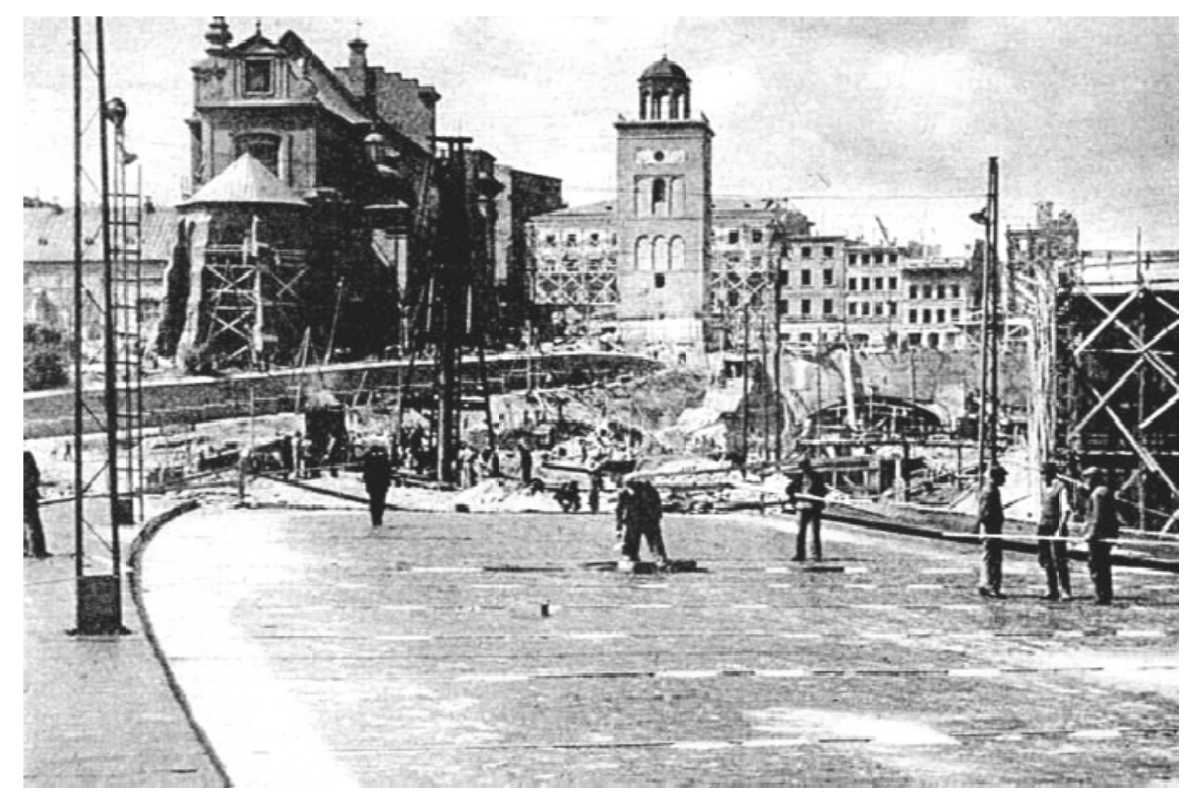

Fig.2. View of the St. Ann's Church during the construction of Warsaw's East-West Route in 1949 (origin PAP)

It should be pointed out that due to existing geological morphological pattern and unfavourable water conditions in the proximity to the slope there is a possibility of slope slide near the temple foundation due to unstable subsoil.

Inclinometric measurements were applied to detect changes in the slope at different levels. In order to achieve that two $14 \mathrm{~m}$ deep inclinometric columns were embeded beneath ground level (Fig. 3.). 


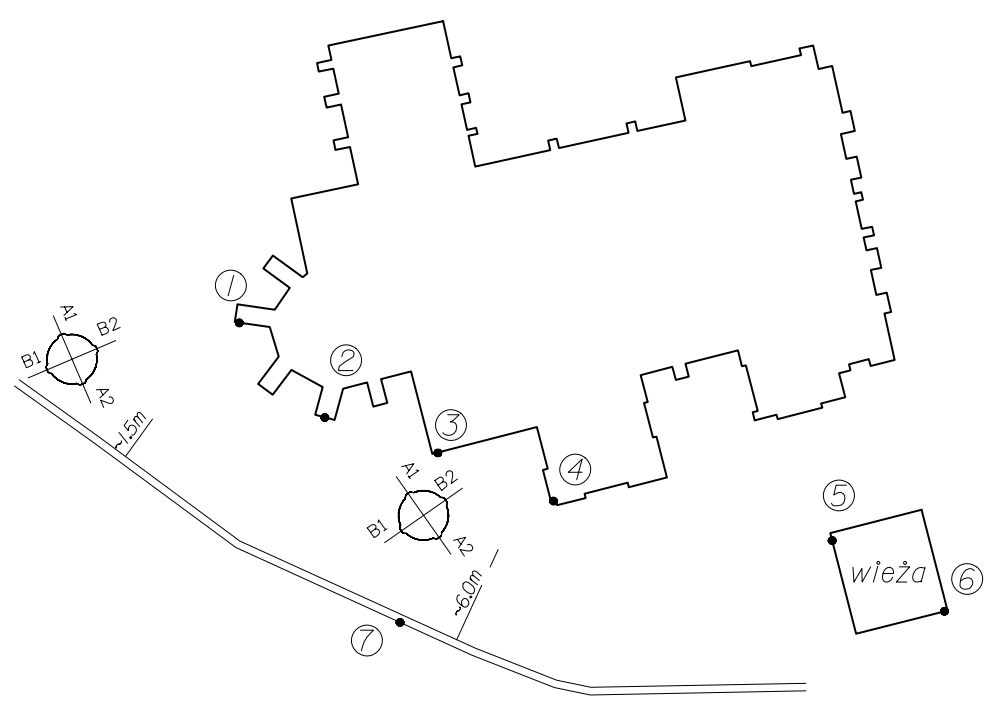

Fig. 3. The sketch of the location of inclinometer columns

\section{Investigating the accuracy of the horizontal relative ground displacements by SISGEO S242SV30 probe}

It is a common practice to evaluate data collection accuracy according to specified by instrument manufacturer precision in the instructions manual of an electronic device.

Here, we avail ourselves an opportunity to present an easy procedure to evaluate measurement results taken with an inclinometric probe.

The probe under test operates on two servo-accelerating converters detecting simultaneously angular "zero offset" in two perpendicular planes.

Inclinometer measurements observations are taken in two reverse positions of probe as a routine procedure to have an independent check and index error estimation. Obtained double (twin) observations allow accuracy determination because the total of results yields double "zero offset" as an index error. Values of index error as calculated from all measurements taken, and are determined by standard formula :

$$
c_{i}=\frac{1}{2}\left(O_{1}+O_{2}\right) \text {. }
$$

Mean square error of singular index error "zero offset" estimated by residuals is determined by the formula:

where : $v_{i}=C_{m}-c_{i}$.

$$
m_{C}=\sqrt{\frac{\left[v_{i} v_{i}\right]}{n-1}}
$$

Then, the mean square error of singular observation is given by: $\boldsymbol{m}_{\boldsymbol{O}}=\boldsymbol{m}_{C} \sqrt{2}$.

It was set as a task to determine precision of those relative horizontal displacements. To this respect 5 sets of measurements with two inclinometer columns were performed at the sliding slope of St Ann's Church Hill commencing from March 8th 2011 up to January 2nd 2012. As a result we achieved the mean square error of single observation $m_{0}=41 "$. This is equivalent to relative error of $0.10 \mathrm{~mm} / 0.5 \mathrm{~m}$.

It must be stated that obtaining such a high accuracy is possible only with data debugging procedure. To this purpose it is essential to carry out observations with double axis Probe at 4 positions at $90^{\circ}$ apart each time. Results of testing are presented in table below. 
Table 1. Results of testing of accuracy of the horizontal relative ground displacements

\begin{tabular}{|c|c|c|c|c|c|c|c|c|c|c|c|c|c|c|c|c|c|c|c|c|}
\hline \multirow[b]{3}{*}{ Section } & \multicolumn{20}{|c|}{ COLUMN 1} \\
\hline & \multicolumn{4}{|c|}{$8.03 .2011 \mathrm{r}$} & \multicolumn{4}{|c|}{$26.04 .2011 \mathrm{r}}$. & \multicolumn{4}{|c|}{$14.07 .2011 \mathrm{r}$. } & \multicolumn{4}{|c|}{$24.10 .2011 \mathrm{r}$} & \multicolumn{4}{|c|}{$2.01 .2012 \mathrm{r}$} \\
\hline & $\begin{array}{l}\mathrm{C}_{\mathrm{m}} \\
{\left[{ }^{\prime \prime}\right]}\end{array}$ & $\begin{array}{l}\mathrm{m}_{\mathrm{C}} \\
{["]}\end{array}$ & $\begin{array}{r}\mathrm{m}_{\mathrm{O}} \\
{[\mathrm{mm}]}\end{array}$ & $\mathrm{n}_{\mathrm{G}}$ & $\begin{array}{l}\mathrm{C}_{\mathrm{m}} \\
{\left[{ }^{\prime}\right]}\end{array}$ & $\begin{array}{l}\mathrm{m}_{\mathrm{C}} \\
{["]}\end{array}$ & $\begin{array}{r}\mathrm{m}_{\mathrm{O}} \\
{[\mathrm{mm}]}\end{array}$ & $n_{G}$ & $\mathrm{C}_{\mathrm{n}}$ & $\begin{array}{l}\mathrm{m}_{\mathrm{C}} \\
{["]}\end{array}$ & $\begin{array}{r}\mathrm{m} \\
{[\mathrm{mm}}\end{array}$ & & $\begin{array}{l}\mathrm{C}_{\mathrm{n}} \\
{\left[{ }^{2}\right]}\end{array}$ & $\begin{array}{l}\mathrm{m}_{\mathrm{C}} \\
{["]}\end{array}$ & $\begin{array}{r}\mathrm{m}_{\mathrm{O}} \\
{[\mathrm{mm}]}\end{array}$ & $\mathrm{n}_{\mathrm{G}}$ & $\begin{array}{l}\mathrm{C}_{m} \\
{[m]}\end{array}$ & $\begin{array}{l}\mathrm{m}_{\mathrm{C}} \\
{\left[{ }^{\prime}\right]}\end{array}$ & $\begin{array}{r}\mathrm{m}_{\mathrm{O}} \\
{[\mathrm{mm}]}\end{array}$ & \\
\hline$\overline{A 1}-\mathrm{A} 3$ & 68 & 57 & 0.10 & - & - & - & & - & 72 & 60 & 0.1 & & 68 & 61 & 0.11 & & 80 & 51 & 0.09 & \\
\hline & 402 & 41 & 0.07 & - & -423 & 83 & 0.15 & 1 & -436 & 44 & 0.0 & & -430 & 57 & 0.10 & & -435 & 33 & 0.06 & \\
\hline $\mathrm{A} 2-\mathrm{A} 4$ & 55 & 66 & 0.12 & 1 & 91 & 63 & 0.11 & 1 & 7 & 59 & 0.1 & & 70 & 68 & 0.12 & 1 & 61 & 60 & 0.11 & \\
\hline $\mathrm{B} 2-\mathrm{B} 4$ & 404 & 51 & 0.09 & & -416 & 42 & 0.07 & & -437 & 43 & 0.0 & & -434 & 39 & 0.07 & & -436 & 33 & 0.06 & \\
\hline
\end{tabular}

\begin{tabular}{|c|c|c|c|c|c|c|c|c|c|c|c|c|c|c|c|c|c|c|c|c|}
\hline \multicolumn{21}{|c|}{ COLUMN 2} \\
\hline \multirow[b]{2}{*}{ ection } & \multicolumn{4}{|c|}{$8.03 .2011 \mathrm{r}$. } & \multicolumn{4}{|c|}{$26.04 .2011 \mathrm{r}$. } & \multicolumn{4}{|c|}{$14.07 .2011 \mathrm{r}$} & \multicolumn{4}{|c|}{ 24.10.2011r. } & \multicolumn{4}{|c|}{$22.12 .2011 \mathrm{r}$} \\
\hline & $\begin{array}{l}\mathrm{C}_{\mathrm{m}} \\
{\left[{ }^{\prime \prime}\right]}\end{array}$ & $\begin{array}{l}\mathrm{m}_{\mathrm{C}} \\
{["]}\end{array}$ & $\begin{array}{r}\mathrm{m}_{\mathrm{O}} \\
{[\mathrm{mm}]}\end{array}$ & & $\begin{array}{l}\mathrm{C}_{\mathrm{m}} \\
{["]}\end{array}$ & $\begin{array}{l}\mathrm{m}_{\mathrm{C}} \\
{["]}\end{array}$ & $\begin{array}{r}\mathrm{m}_{0} \\
{[\mathrm{~mm}]}\end{array}$ & $\mathrm{G}$ & $\begin{array}{l}\mathrm{C}_{\mathrm{m}} \\
{["]}\end{array}$ & $\begin{array}{l}m_{C} \\
{["]}\end{array}$ & $\begin{array}{r}\mathrm{m}_{0} \\
{[\mathrm{~mm}]}\end{array}$ & $\mathrm{n}_{\mathrm{G}}$ & $\begin{array}{l}\mathrm{C}_{\mathrm{m}} \\
{["]}\end{array}$ & $\begin{array}{l}\mathrm{m}_{C} \\
{["]}\end{array}$ & $\begin{array}{r}\mathrm{m}_{0} \\
{[\mathrm{~mm}]}\end{array}$ & $n_{G}$ & $\begin{array}{l}\mathrm{C}_{\mathrm{m}} \\
{\left[{ }^{\prime \prime}\right]}\end{array}$ & $\begin{array}{l}\mathrm{m}_{\mathrm{C}} \\
{\left[{ }^{\prime \prime}\right]}\end{array}$ & $\begin{array}{r}\mathrm{m}_{0} \\
{[\mathrm{~mm}]}\end{array}$ & $\mathrm{n}_{\mathrm{G}}$ \\
\hline$\overline{\mathrm{A} 1}$ & 63 & 62 & 0.11 & & 77 & 50 & 0.09 & & 66 & 45 & 0.08 & & & & & & 105 & 40 & 0.07 & \\
\hline & -392 & 56 & 0.10 & & -408 & 32 & 0.06 & & -432 & 34 & 0.06 & & & & & & -420 & 43 & 0.08 & \\
\hline $\mathrm{A}_{2}-\mathrm{A}^{2}$ & 65 & 69 & 0.12 & 1 & 77 & 54 & 0.10 & & 62 & 77 & 0.14 & 2 & 83 & 80 & 0.14 & 2 & 164 & $\mid 63$ & 0.11 & 1 \\
\hline $\mathrm{B} 2-\mathrm{B} 4$ & 400 & 36 & 0.06 & & -406 & 32 & 0.06 & & -425 & 33 & 0.06 & & -424 & 30 & 0.05 & & -423 & $32 \mid$ & 0.06 & \\
\hline
\end{tabular}

The table 1 shows listed for each survey:

$C_{m}$ - mean value of index error "zero offset",

$m_{C}$ - mean square error of single observation of index error,

$m_{0}$ - mean square error of single observation,

$n_{G}$ - frequency number of blunders.

In the analysis index error /"zero offset"/ was regarded as instrumental non discarded angular residual . Error in reading related to Probe inclination at the distance of $0.5 \mathrm{~m}$ is quoted in millimetres. Real reading at display is a product of $20000 \sin \alpha$.

Before final evaluation of precision, blunder detection and elimination was carried out according to criterion $\frac{m_{c}}{c}>3$.

\section{Inclinometer measurements for relative horizontal displacement grounds at Warsaw hillside st. Anna's church}

In order to detect possible ground slide movements at hill slope, two inclinometers were fixed in the hill of St Ann's Church in Warsaw, and observations were commenced on March 8, 2011. Consecutive series of measurements were taken on: April 26, July 14, October 24, and January 2, 2012.

Inclinometer measurement results in specified directions are presented on diagrams in Fig. 4. These diagrams present isolated geological strata (kind of soils) encountered at the site of inclinometer investigations.

The foot of column No.1 is located about $6 \mathrm{~m}$ beneath adjacent hillside Nowy Zjazd street carriageway, and the column No.2 was embedded $3.5 \mathrm{~m}$ beneath the carriageway of Trasa W-Z (W_Z Throughway). Feet of the columns were embeded in Tertiary period half coarse silty clay, and hard silty clay. 

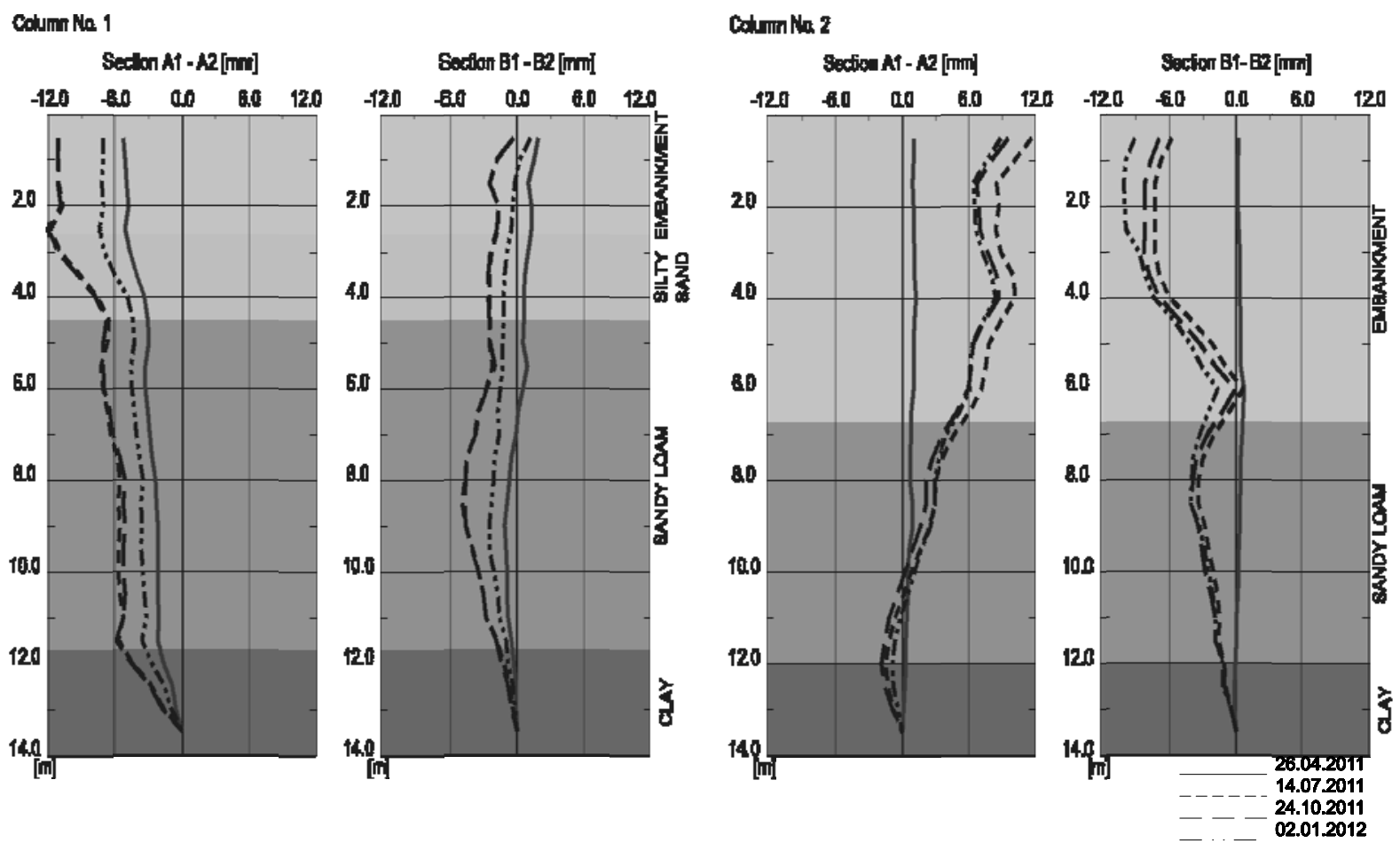

Fig. 4. The graphs of horizontal displacement in relation to hill side foot

Observations of inclinometer No.1 indicate relative horizontal ground displacements. It is well seen from diagram in Fig. 4 a displacement trend due to heavy rainfall spell, which subsides during the period from July to October.

Data collected with inclinometer No.2 indicate existence of relative ground displacement. Displacement trends towards retaining wall are distinct. In the period from October 2011 up to January 2012 reverse trend is evident. In the upper part of column sheltered by $5.5 \mathrm{~m}$ thick retaining and unsheltered (exposed) part at $3 \mathrm{~m}$ height could be explained by thermal expansion. One has to notice that ground consists mainly of sand and brick rubble in this area. Noticeably, there is change of displacement trend from the base of column at the depth of $11.5 \mathrm{~m}$ cross section A1-A2 and for cross section B1-B2 at the depth of $9 \mathrm{~m}$. It is supposed that the column gets through a layer of Tertiary Period silty clay. Relative horizontal displacements referring to level depth of $11.5 \mathrm{~m}$ are presented in Fig 5.

This example shows how crucial is in ground deformation measure-ments and slope ground deforma-tion measurements, adequate positioning of inclinometer column base.

Data collected with inclinometer No.2 indicate existence of relative ground displacement. Displacement trends towards retaining wall are distinct.

In case of positioning column No.1 at the same reference level instead of column No.2 any significant change in displacement of ground at the adjacent layers of clay and sandy loam could have be found. 

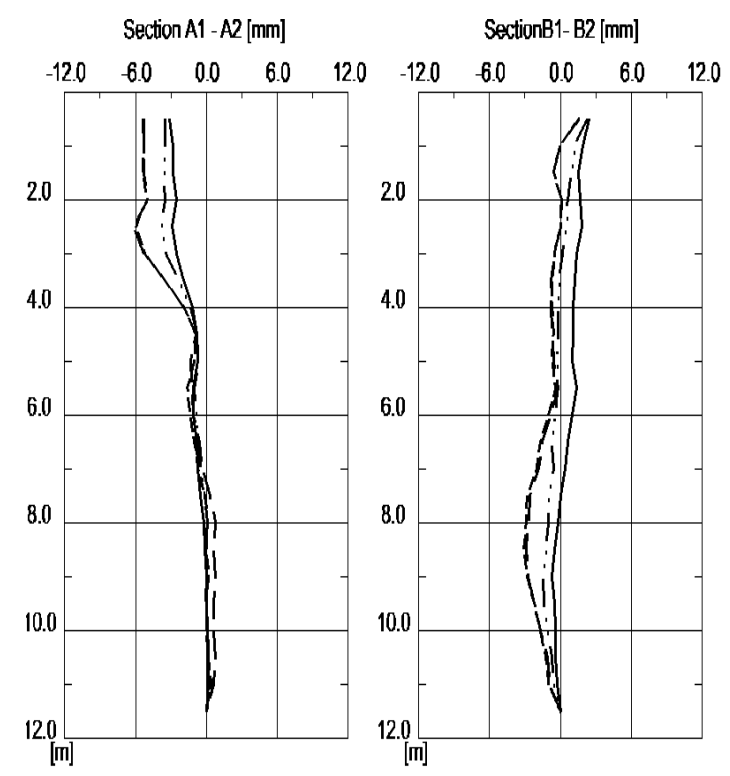

Fig 5. The graph of relative horizontal displacements referring to level depth of $11.5 \mathrm{~m}$ in column No.1

Appraisal of this phenomenon could be substantially facilitated if absolute horizontal displacement of inclinometer column head is known.

Absolute horizontal displacements in columns No.1 and No.2 are presented on diagrams in Fig 6.

Above values are obtained as a result of including inclinometric column heads readings to angular-distance net. The net was established to determine absolute horizontal displacements of objects located at St Ann's Church Hill.

Taking comparison between relative displacements [Fig 4] and absolute displacements [Fig 6] one can easily notice that detected changes take place in a clay layer spread over several meters under ground surface.
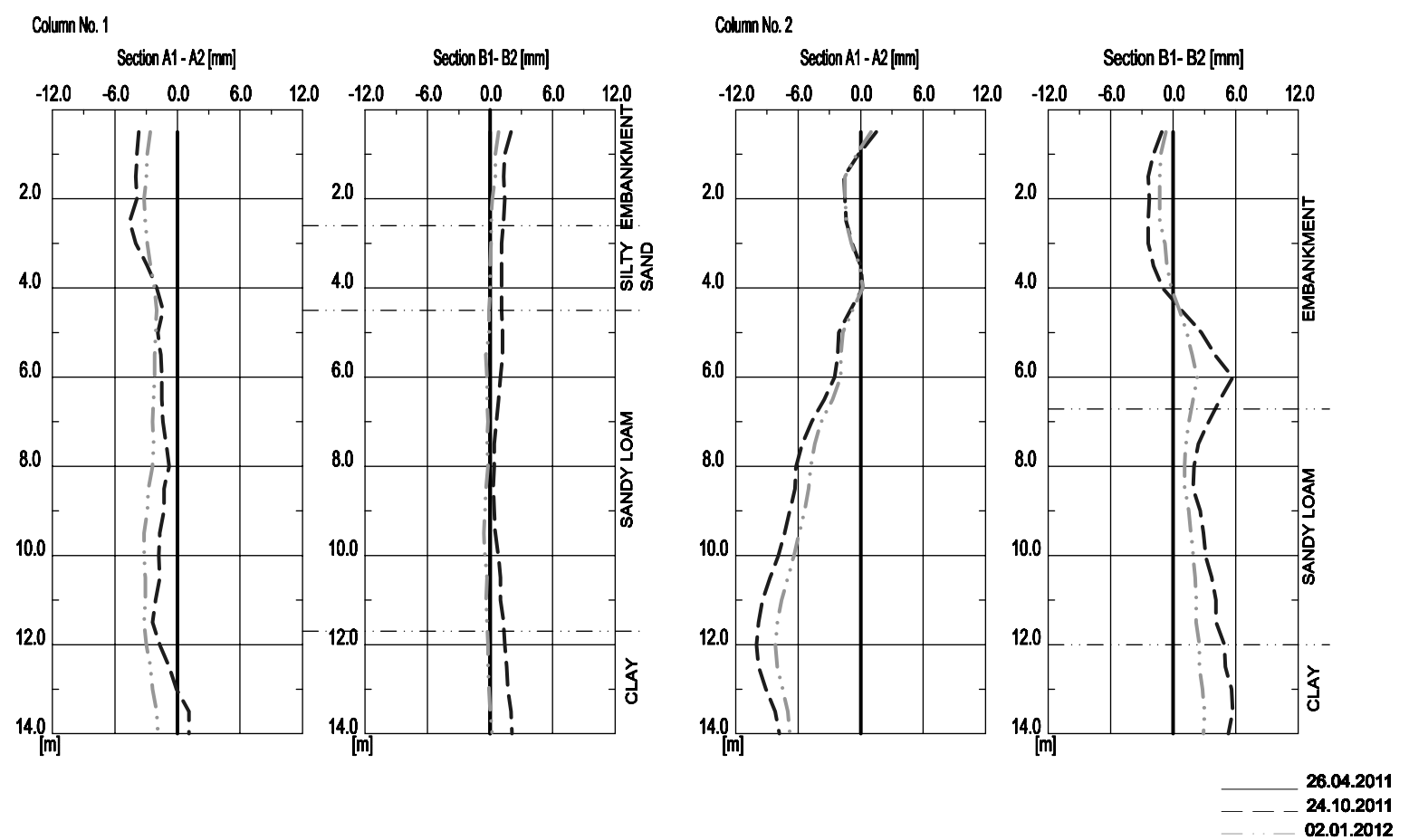

Fig. 6. The graphs of absolute horizontal displacements in column No.1 and No.2 


\section{Conclusion}

Mean errors or relative horizontal displacement with double axis probe SISGEO S242SV30 at two perpendicular cross-sections do not exceed $0.6 \mathrm{~mm}$ of $10 \mathrm{~m}$ column depth.

It is a must to have a check during data collection and data processing on observation of index error /"zero offset"/ constancy value obtained from double position of probe.

To eliminate blunders or gross errors, it is essential prior to observation takings, to define junction places of pipes on the basis of assembly works or experimental surveys, for adequate positioning of probe.

Inclinometer observations should be extended and supplemented by absolute horizontal displacement measurements of inclinometer head to asses thoroughly ground position changes.

Analysis of inclinometric columns axis inclination indicate significant relation link to geological strata location and pattern in the slope.

It was proved essential to carry out detailed soil mechanics investigations of slope and adjacent grounds prior to column location in order to select its due horizontal position and vertical foundation.

\section{References}

Malarski, R., Łapinski, S., Nagórski, K., Pasik, M. \& Woźniak, M., (2011). Badanie przemieszczeń poziomych i pionowych Kościoła Akademickiego Św.Anny w Warszawie (Investigations horizontal and vertical displacements St.Ann's Academic Church in Warsaw), Description for Heritage Protection Department City of Warsaw, Politechnika Warszawska

SISGEO S.r.I., (2006). Inclinometers, Instructions manual, Italy

Wolski, W., Furstenberg, A. \& Sorbjan, P., (2007). Inclinometer Measurements applied to assessment of structures safety state. Papers XXIII Conference on "Structure Damages of 2007".

\section{Authors:}

Ryszard Malarski ${ }^{1}$, PhD., r.malarski@gik.pw.edu.pl

Kamil Nagórski ${ }^{1)}$, Msc., k.nagorski@gik.pw.edu.pl

Marek Woźniak ${ }^{1)}$, Prof., m.wozniak@gik.pw.edu.pl

1) Faculty of Geodesy and Cartography, Department of Engineering Surveying,

Warsaw University of Technology, Poland 